\title{
Author's prospect and plot perspective in the closed-in construction of an oratorical speech
}

\author{
Kapitolina Ulanova $^{1 *}$, Nailya Valeeva $^{1}$ \\ ${ }^{1}$ Peoples' Friendship University of Russia, 117198, Miklukho-Maclaya str.6, Moscow, Russian \\ Federation
}

\begin{abstract}
The article deals with the problem of creating a public oratorical speech. This research is based on an extensive literary analysis of such scientists in the field of text as I.G. Koshevaya (Koshevaya, 2012), L L. Nelyubin (Nelyubin, 2011), L.K. Sviridova (Sviridova,2004), G.T. Khukhuni (Khukhuni, 2011). The purpose of the research is to analyze the relationship between the author's prospect and the plot perspective of the oratorical text. During the research, we used the following methods: the method of contextual analysis, the method of dictionary definitions, the descriptive method, and the method of continuous sampling when selecting material for research. We have selected, counted, and systematized speeches from more than 1000 pages of texts of public speeches. The results of the research can be used in writing academic and political oratorical texts, as well as in courses of rhetoric for University students.
\end{abstract}

\section{Introduction}

The construction of a public oratory, despite the fact that each of the speeches is uniquely individual, has some typological common features. This is due to the fact that the main idea of the speech of a member, it breaks down in the text into a number of structural elements, each of them is a kind of center around which a segment of the speech text intended for the disclosure of this idea is combined. To understand the essence of the content side of the speech, it is necessary to highlight such key moments with the help of which, on the one hand, the idea (its element) is encoded, and on the other, the general direction of the plot perspective of the speech text is determined.

Creating an oratorical speech, the author highlights some of the most important points a kind of reference points (main ideas), the description of which is necessary for the most complete representation of the General idea of the oratorical speech, that is, for a figurative description of the idea. The latter involves specifying the language methods by which the closest possible contact with the audience should be established precisely at the moment when the code expression of each component of the idea is transmitted to the listeners.

\footnotetext{
* Corresponding author: ulanova-kl@rudn.ru
} 


\section{Methods}

In an orator's speech, in our opinion, the author's perspective deserves special attention, understood as a special psycholinguistic complex based on a direct or improperly direct address of the speaker to the listener. The author's perspective, as a concept, was introduced into linguistic use by Professor I.G. Koshevaya, who understands the mock-content basis of the text by the author's prospect, which can represent both the most concise idea of the text, and a significant speech work with more or less details included in it [1].

The author's prospect, without affecting or significantly changing the main line of the narrative, supplements it with a number of author's details, that is, mentally constructs an extremely real picture in real time and space. The author's perspective makes the abstract at the beginning, at the stage of speech conception, the orator's speech concrete. In the author's imagination, a model of his future speech, gradually becoming more and more clear, appears, from the first to the last word, glance or deed, in a strict logical sequence, subordinate to the author's intention.

\section{Results}

Based on the foregoing, in our opinion, the following features of the author's perspective can be distinguished:

1. The speaker's presentation of the storyline of speech with a narrowing or expanding set of details, which, in the process of preparing the text, will turn into speech situations of a more or less broad plan.

2. Evaluation of these details from a certain author's, personal, worldview position, which the author will try to convey during the speech, through reasoning and evidence to the listener, attracting him to his worldview camp, trying to make him his like-minded person, to evoke intellectual and emotional empathy.

In other words, the author's perspective is the meaningful frame of a public speech, which the author of the speech (orator) imagines in a holistic manner up to its figurative embodiment in the text and regardless of the interpretation of speech situations. Therefore, the author's perspective is a linear representation of the content of the entire speech prepared by the speaker. The author's perspective includes the real boundaries of the phenomenon or object considered in the oratorical presentation, the idea of the real beginning and the real end of the oratorical text being created. Moreover, for the author of an oratorical text, the beginning and end of the text are present in real time and space, are their components.

Thus, the author's perspective is a reflection of the content that the author wants to communicate to the listener, for which he creates his oratorical work. But the author's idea of this object is twofold; the speaker sees the object: 1) as it is; 2) as it should, in his opinion, appear in the oratorical speech. And this second plan, although closely related to the first, does not fully correspond to it, going beyond the author's perspective and forming a plot perspective of speech. We presented the structure of the author's perspective in the form of a diagram in figure 1 . 


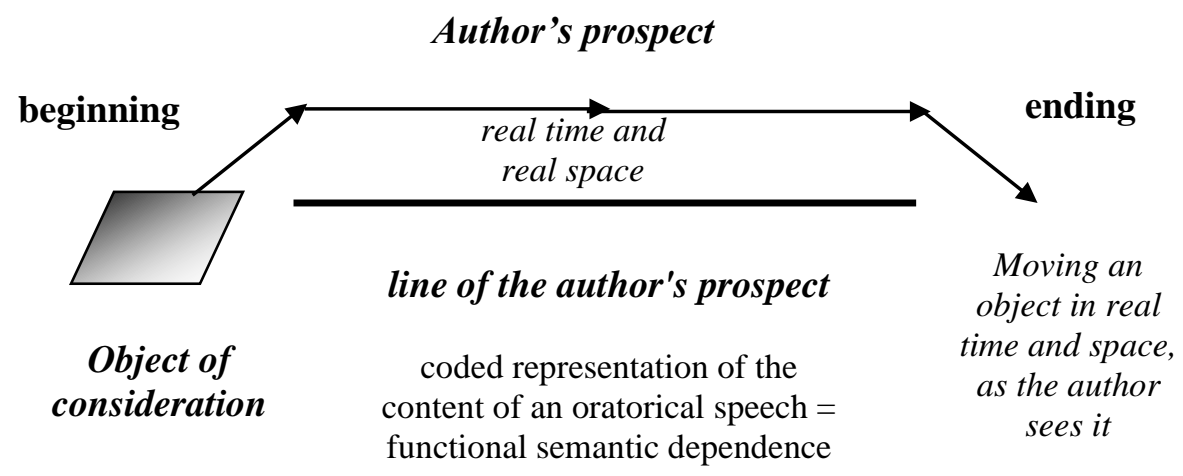

Fig. 1. Author's prospect.

The author's prospect is the content of the oratorical text planned and created by the author, which unfolds in a linear, syntagmatic way, as a direct sequence of events (components of the speech) one after another. The author's prospect is the content of speech that the author imagines to be the most adequate, keeps in mind and seeks to embody through the plot perspective created by him. The author's prospect is the content base that guides the speaker's thought, which allows him to clearly imagine the framework of the speech, to be consistent, not to deviate from the perspective of the developing line of action on non-essential elements.

Therefore, the author's prospect is linearly one-dimensional, implemented in a linear sequence of units. Plot perspective is a phenomenon of a completely different plan; according to I. G. Koshevaya, it is a phenomenon derived from the author's prospect and at the same time dependent on it [2]. Thanks to the plot perspective, the speaker forms the architectonics of public speech, for example, makes the necessary structuring of the text, placing the components aimed at revealing the content of speech in a certain sequence.

In other words, in contrast to the author's prospect, which is linear and syntagmatic, the plot perspective has volume and multidimensionality. Writing certain types of speech complexes into the outline of a speech situation, the plot perspective is based not on real time, but on artistic time [3]. As a result, in the course of speech, an action unfolds that takes place not in the real, but in the artistic space.

The plot perspective is parameterized in a different way compared to the author's prospect. It is imposed on the author's prospect, but may modify, change object of consideration independently, and depending on the moments in the storytelling, which the author can achieve maximum attention and interest from the listener and attract his attention. The plot perspective in comparison with the author's perspective is not a planned, but a real deployment of speech, depending on the external conditions of the speaker's utterance and the audience's perception of it. In figure 2, we presented the plot perspective schematically. 


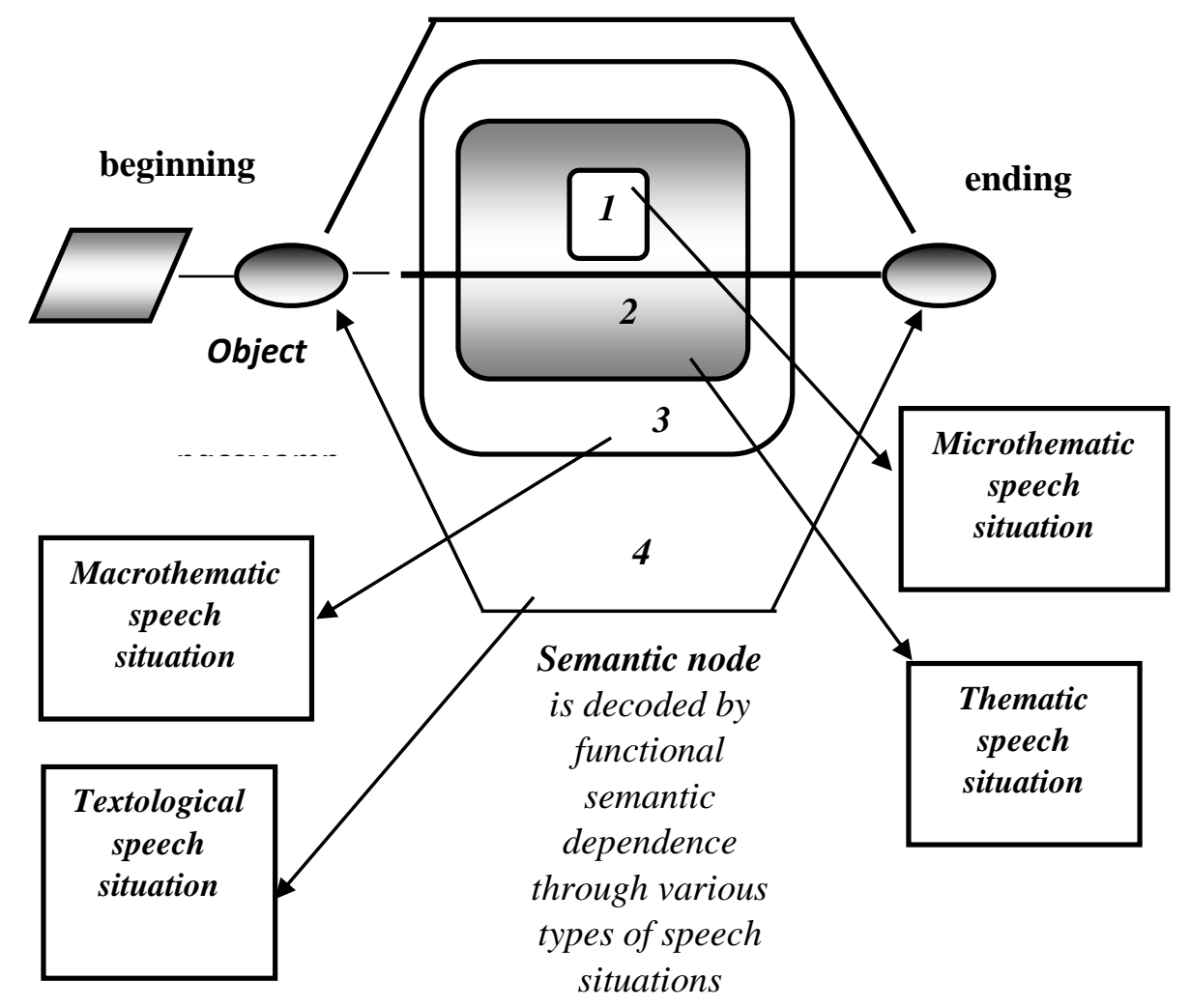

Fig. 2. Plot perspective.

In terms of content, it is the semantic node that actually contributes to the disclosure of real semantic space and semantic time, since it concentrates the textual speech situation (corresponding to the entire oratorical text), which is an integral element of the category of identity and which contributes to the embodiment of artistic space and artistic time as the basis of the entire speech, the entire speech as a whole[4].

The relationship between the author's prospect and the story perspective, considered by us, allows us to note that the text is a structural and semantic unity that serves to Express an idea (problem), based on the category of identity of the beginning and end of the text, as well as on the story perspective, which allows the author to design a different, to varying degrees successful location of each semantic node of the text in relation to the central links of speech, its core and invariants[5]. To preserve the adequacy of the original idea of the text, which is expressed in the beginning and at the end of the speech, the speaker cannot go beyond the category of identity. Therefore, we can talk about a hierarchical, subordinate relationship between the author's perspective and the category of identity.

In our opinion, the author's prospect is realized in the speaker's speech, where it is influenced by two factors:

1. The semantic component of the text, which limits the effect of functional semantic dependence. 
2. Intentions of the author who selects the signs of the language system at the second level of abstraction.

\section{Conclusion}

Thus, the author's prospect in oratory limits the functional semantic dependence, the subordination of which to the author's prospect is manifested by focusing thoughts on such key points of the author's perspective as the invariant, the core, the central link and the semantic node. In addition, the functional semantic dependence is based on the author's prospect, since, only the invariant expresses it one-dimensionally.

\section{Acknowledgments}

This work was supported by the Russian Foundation for Basic Research, grants No. 15-3410488, 17-34-10303 and 20-012-22046.

\section{References}

1. I.G. Koshevaya, Text-forming structures of language and speech, Ed. 2nd., Book house "LIBROKOM", Moscow (2012)

2. I.G. Koshevaya, L.K. Sviridova Grammatical structures and categories of the English language: a Theoretical course. Book house "LIBROKOM", Moscow (2010)

3. L.L. Nelyubin, G.T. Khukhuni History of the science of language. 4th ed., Stereotyped. Flinta: Nauka,_Moscow (2011)

4. L.K.Sviridova The role of emotional structures in the implementation of the category of identity in the construction of a dramatic text: dis. ... doctor in philology: specialty 10.02.19, MGOU, Moscow (2004)

5. L.K. Sviridova The role of pause in the emotional and semantic organization of utterance. RUDN Bulletin series Questions of education. Language and specialty, no. 5. Moscow (2007) 